\title{
PEMBERDAYAAN MASJID. UPAYA MEMBENTENGI GENERASI PENERUS DARI EFEK NEGATIF PERKEMBANGAN ZAMAN DUSUN KRAPYAK WETAN, PANGGUNGHARJO, SEWON, BANTUL
}

\author{
Oleh: \\ Hendro Widodo Mahasiswa KKN Alternativ LVI unit II.B.2 \\ Universitas Ahmad Dahlan
}

\begin{abstract}
Ringkasan
Pergaulan remaja saat ini sudah memasuki babak yang lebih berbahaya daripada tahuntahun sebelumnya. Kita dapat menyaksikan banyaknya tindak kriminalitas ataupun kenakalankenakalan reamaja yang ada disekitar kita. Remaja saat ini banyak menirukan tindakan-tindakan yang tidak pantas yang ada di internet maupun media lainnya. Kebanyakan anak-anak maupun remaja kurang memiliki bentang yang kuat dalam diri mereka untuk membentengi diri dari pengaruh dunia luar. Di Dusun Krapyak Wetan yang merupakan perbatasan daerah kota dengan desa dimana msyarakatnya sudah heterogen menimbulkan banyak masuknya budaya dari luar ke Dusun Krapyak Wetan. Memberdayakan kegiatan masjid bagi generasi muda merupakan salah satu upaya membentengi generasi muda dari dampak negatif perkembangan zaman.
\end{abstract}

Kata kunci: Pergaulan Remaja, Pemberdayaan Masjid.

\begin{abstract}
Abstrak
Today's teenagers have entered a more dangerous phase than in previous years. We can witness the many acts of criminality or the mischiefs of reamaja around us. Adolescents today imitate many inappropriate actions that exist on the internet and other media. Most children and adolescents lack a strong span within themselves to fortify themselves from the influence of the outside world. In Krapyak Wetan hamlet which is the border of the city with the village where the community has been heterogeneous has caused a lot of cultural influx from outside to Krapyak Wetan Hamlet. Empowering mosque activities for the younger generation is one effort to fortify the younger generation of negative impacts of the times.
\end{abstract}

Keywords: Youth Association, Mosque Empowerment

\section{A. PENDAhuluan}

Saat ini kenakalan remaja menunjukkan trend yang amat memprihatinkan. Kenakalan remaja bukan hanya terjadi di kota-kota besar saja tetapi sudah merambah sampai di kota-kota kecil dan daerah pedesaan. Kenakalan remaja yang diberitakan berbagai media massa dianggap makin meresahkan dan membahayakan masyarakat. Beberapa contoh, ulah remaja belakangan ini makin mencemaskan masyarakat. Mereka tidak lagi sekadar terlibat dalam aktivitas nakal seperti membolos sekolah, merokok, minum-minuman keras, atau menggoda lawan jenisnya, tetapi tak jarang mereka terlibat dalam aksi tawuran layaknya preman, penjambretan, pemerasan, pencurian, perampokan, penganiayaan, perkelahian secara perorangan atau kelompok, mabuk-mabukan, penyalahgunaan obat-obatan seperti narkoba, terjerumus dalam kehidupan seksual pranikah, dan berbagai bentuk perilaku menyimpang lainnya.

Melihat kondisi yang ada disekitar kita terlebih lagi ada indikasi kenakalan remaja diduga disebabkan banyak faktor, diantaranya berkaitan dengan religiusitas mereka. Ada 
dugaan hubungan antara religiusitas dengan kenakalan remaja, jika tingkat religiusitasnya tinggi maka tingkat kenakalan remaja semakin rendah. Tetapi tidak menutup kemungkinan meskipun ada sebagian dari mereka yang memiliki religiusitas tinggi tetapi mereka tetap terbawa arus trend kenakalan remaja. Di daerah perbatasan perkotaan atau daerah yang sedang transisi menuju kondisi perkotaan seperti di Dusun Krapyak Wetan akan mendapat banyak budaya baru yang masuk dengan mudah. Tanpa adanya kontrol diri dalam setiap individu, bukan tidak mungkin akan muncul kenakalan-kenakalan remaja pada masyarakat.

Melihat permasalahan tersebut Mahasiswa KKN UAD (Universitas Ahmad Dahlan) periode 56 Unit II.B.2 menyusun sebuah program yang diharapkan dengan program tersebut adalah solusi untuk membentengi generasi muda dari masuknya budayabudaya yang dapat menyebabkan kenakalan remaja. Program yang disusun tergabung dalam pemberdayaan kegiatan masjid Al-Amien untuk anak-anak dan remaja, dengan salah satu program unggulan Malam Bina Iman dan Taqwa bagi anak-anak dan remaja masjid.

Mulyadi, dkk (2006) mendefinisikan kenakalan remaja sebagai keinginan untuk mencoba segala sesuatu yang kadang-kadangmenimbulkan kesalahan-kesalahan yang menyebabkan kekesalan lingkungan dan orangtua. Hal ini lah yang kemudian menjadikan remaja menjadi lebih susah diatur. Mereka ingin mencoba hal-hal yang baru yang mereka belum tau resiko dari hal-hal tersebut. Masa-masa inilah yang perlu kita waspadai.

Kegiatan-kegiatan religius seperti Malam Bina Iman dan Tawa diperlukan untuk memberikan kontrol diri pada anak-anak dan remaja sehingga mereka tidak melakukan kenakalan-kenakalan yang saat ini marak terjadi masyarakat. Sikap religius juga diajarkan melalui pendidikan. Menurut pendidikan nasional (Syamsul Kurniawan, 2014: 41) menyampaikan 18 nilai-nilai karakter yang diharapakan tercapai dalam pendidikan karakter. Sikap religius berada pada posisi teratas dari 18 nilai tersebut. Hal ini menjelaskan bahwa sikap religius sangat lah penting untuk dimiliki setiap orang.

\section{B. PELAKSANAAN}

Pelaksanaan mabit ini dimulai dengan sosialisai kepada calon peserta bahwasanya akan diadakan mabit. Dalam mensosialisaikan kegiatan ini disampaikan pula materi tentang kegiatan yang akan dilakukan waktu kegiatan mabit. Kemudian dilakukan pendaftaran untuk mendata seluruh peserta yang ingin mengikuti mabit. Setelah terdata, peserta akan dibagi menjadi kelompok. Setiap kelompok tersebut memiliki 1 pendamping dari remaja masjid yang lebih tua untuk menjadi penanggung jawab.

Kegiatan mabit dimulai pukul ashar dan direncanakan selesai setelah subuh. Peserta akan diberi kegiatan berupa sholat berjamaah, permainan, tadarus Al-Quran, dan setelah tarawih diadakan jurit malam dengan sistem pos. Setiap pos diberi materi tentang agama dan game untuk kerjasama. 
Diterbitkan oleh Lembaga Pengabdian kepada Masyarakat

Universitas Ahmad Dahlan Yogyakarta

\section{HASIL, PEMBAHASAN, DAN DAMPAK}

1. Deskripsi Wilayah (Letak dan Luas Wilayah)

Dusun Krapyak Wetan terletak di Kecamatan Sewon, Bantul. Kelurahan Panggungharjo adalah salah satu keluharan yang ada didusun Krapyak Wetan, kelurahan Panggungharjo termasuk salah satu sub unit kerja KKN Alternatif periode LVI UAD tahun akademik 2016/2017. Wilayah Dusun Krapyak Wetan terletak dikecamatan Sewon kabupaten Bantul dengan batas - batas wilayah sebagai berikut batas sebelah utara dusun Jogokaryan, batas sebelah timur Dusun Salakan, batas sebelah selatan Dusun Salakan, batas sebelah barat Dusun Krapyak Kulon.

Jumlah keseluruhan penduduk dusun Krapyak Wetan adalah 153 orang dengan jumlah penduduk laki-laki 73 orang dan penduduk perempuan 80 orang. Dari data yang didapatkan bahwa sebagian penduduk dusun Krapyak Wetan bekerja sebagai pegawai/buruh di berbagai perusahaan/industri. Namun ada beberapa warga yang memiliki mata pencaharian dari berbagai pekerjan seperti Pedagang, PNS/ Polri /TNI, Wiraswasta, Karyawan, Petani dsb.

Pendidikan masyarakat Pendowoharjo sudah masuk ke jenjang yang tinggi, sebagian warga telah menempuh pendidikan dengan berbagai gelar. Sedikit warga yang tidak menempuh pendidikan, sebagian dari masyarakat sedang menempuh pendidikan dan yang lainnya masih belum bersekolah.

Agama yang dianut oleh masyarakat di dusun krapyak wetan 95\% Islam. Kehidupan beragama masyarakat setempat cukup baik, terutama untuk kalangan orang tua khususnya ibu-ibu dan bapak-bapak dengan hadirnya dalam jama' ah sholat 5 waktu. Fasilitas keagamaan di dusun Krapyak Wetan, kecamatan Sewon, kabupaten Bantul terdapat ada 5 buah masjid, 4buah mushola, 1 buah pondok pesantren.

2. Hasil Pelaksanaan

Mabit secara bahasa berarti bermalam. Kegiatan mabit terkenal sebagai salah satu rangkaian ibadah haji yaitu mabit/bermalam di Mina. Kegiatan Mabit yang diadakan di Masjid Al-Amien mengadaptasi kegiatan mabit tersebut. Kegiatan ini diadakan dengan melibatkan anak-anak dan remaja yang tergabung dalam remaja masjid. Acara diadakan pada bulan ramadhan.

Konsep acara ini adalah pembelajaran dan penanaman konsep keimanan dan ketaqwaan pada anak-anak dan remaja yang menjadi peserta. Kegiatan ini diisi dengan acara pembelajaran dengan materi materi keislaman. Setiap kegiatan yang dilakukan dilandaskan dengan nilai nilai keislaman. Harapannya setelah kegiatan mabit ini akan berkesan dan selalu diterapkan dalam kehidupan sehari-hari. 


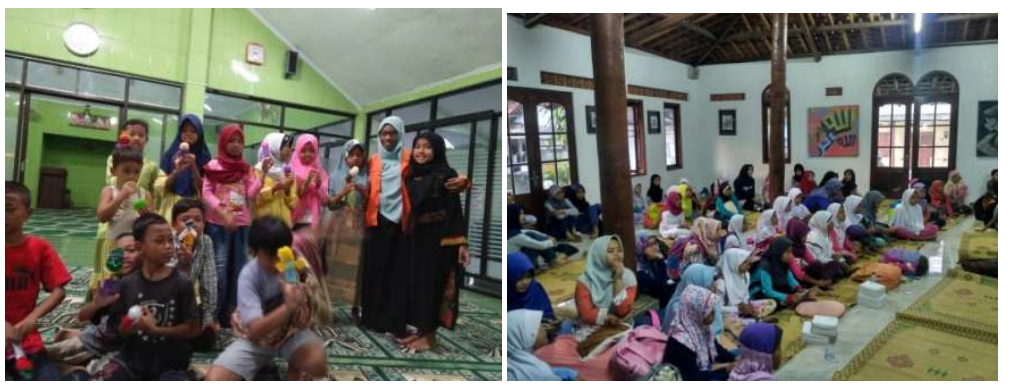

Dokumentasi pelaksanaan Mabit oleh Mahasiswa KKN Alternatif UAD Univ II.B.2

Pada pelaksanaannya remaja diberi pembelajaran supaya mampu mendidik dan membimbing adiknya yang lebih muda. Sedangkan anak-anak dibiasakan akan kehidupan islami agar kehidupannya terhindar dari tindak kenakalan dan hal-hal yang tidak diinginkan.

\section{KESIMPULAN}

Pembekalan tentang religiusifitas menjadikan anak-anak mampu untuk mengontrol diri mereka masing-masing. Dengan mendidik kader remaja masjid untuk dapat membimbing adik-adiknya, diharapkan kegiatan ini menghasilkan generasi muda penerus yang tidak melakukan tindakan-tindakan yang negatif. Berlangsungya acara ini diharapkan mampu memberikan benteng terhadap anak-anak dan remaja yang ada di lingkungan Masjid Al-Amin.

\section{DAFTAR PUSTAKA}

Mulyadi, Seto. (2006). Kekerasan Pada Anak.Dalam http://www.mailarchive.com.

Kurniawan, Syamsul. 2014. Pendidikan Karakter. Yogyakarta: Ar-Ruzz Media. 